CLINICAL STUDY

\title{
Effects of levothyroxine treatment on biochemical and hemostasis parameters in patients with hypothyroidism
}

\author{
Sevim Gullu, Hasan Sav and Nuri Kamel \\ Ankara University, School of Medicine, Department of Endocrinology and Metabolic Diseases, Ibn-i Sina Hospital, Sihhiye O6 100, Ankara, Turkey \\ (Correspondence should be addressed to S Gullu; Email: sevim.gullu@temd.org.tr)
}

\begin{abstract}
Objective: The aims of the study were to evaluate the disturbances in the coagulation system in patients with overt hypothyroidism $(\mathrm{OH})$, to assess the effects of levothyroxine (LT4) on the coagulation parameters, and to determine whether subclinical hypothyroidism ( $\mathrm{SH}$ ) affects concentrations of coagulation markers and several biochemical parameters, thereby supporting early substitution. Design: The study included 15 patients with SH (TSH levels 5-10 mU/l), 15 patients with $\mathrm{OH}$ and 15 euthyroid controls.

Methods: Blood urea nitrogen, creatinine, creatine phosphokinase, aspartate aminotransferase, lactate dehydrogenase, total-cholesterol, high density lipoprotein-cholesterol, low density lipoprotein-cholesterol and triglyceride levels, and bleeding time, prothrombin time (PT), activated partial thromboplastin time (APTT), factor VIII activity, von Willebrand factor activity (vWF), platelet count and clotting time were evaluated just before and three months after the maintenance of euthyroidism with LT4 treatment.

Results: Factor VIII and vWF activities were lower in patients with SH than in controls $(P<0.01)$. Increased bleeding time, PT, APTT and clotting time and decreased factor VIII activity and vWF activity were observed in patients with $\mathrm{OH}$ when compared with controls. Bleeding time, PT, APTT and clotting time decreased and factor VIII activity, vWF and platelet count increased after LT4 in patients with $\mathrm{OH}$. Increases in factor VIII activity and vWF $(P<0.01)$ were detected also in the SH group with treatment.

Conclusions: $\mathrm{OH}$ is associated with significant abnormalities in clotting parameters which are reversed by LT4. In contrast, SH is associated with minor changes in factor VIII activity and vWF which are reversible by LT4. Serum lipids and other measured parameters are not improved by LT4 in patients with TSH $<10 \mathrm{mU} / \mathrm{l}$ and these data fail to demonstrate a need to treat such patients.
\end{abstract}

European Journal of Endocrinology 152 355-361

\section{Introduction}

Thyroid dysfunction, mostly hypothyroidism, is a frequent disorder in the general population, especially among women. Hypothyroid patients may have several hemostatic abnormalities such as modification of the coagulation proteins and bleeding tendency $(1-14)$. A coagulation disorder resembling von Willebrand's disease has been reported in patients with overt hypothyroidism $(\mathrm{OH})(3-8)$. But the influence of hypothyroidism on hemostasis remains controversial since, in addition to these hypocoagulable states, hypercoagulable states have also been reported (10-15). The mechanisms relating to the alterations in the coagulation system in hypothyroidism are not very well established but direct effects of thyroid hormones have been proposed $(10,11,16)$.

Subclinical hypothyroidism (SH) is characterized by increased serum thyrotropin (TSH) levels with normal serum free thyroxine (FT4) and free triiodothyronine (FT3) concentrations. The clinical presentation is nonspecific and symptoms are usually subtle (17-19). Although elevated serum cholesterol concentrations and high risk of atherosclerosis and cardiovascular diseases have been reported in some studies, others have failed to demonstrate those findings in patients with mild thyroid failure $(17-22)$.

Changes in muscle and renal functions and alterations in hemostasis have also been reported in patients with SH (13, 23-27). Although increased factor VII activity, higher fibrinogen and plasminogen activator inhibitor (PAI-1) levels and decreased fibrinolytic activity have been observed in mild and moderate hypothyroidism in previous studies, the influence of SH on hemostasis is not very well known.

Although there is no doubt about the treatment of patients with $\mathrm{OH}$, the decision to treat $\mathrm{SH}$ patients with levothyroxine (LT4) is controversial. The efficacy 
of replacement therapy, especially on the lipid parameters, has shown conflicting results in the English literature $(17,28-37)$. This discrepancy about treatment seems to have resulted from variations in the TSH levels of the selected populations.

The aims of this study were to evaluate the potential association between $\mathrm{OH}$ and disturbances in the coagulation system and to determine whether concentrations of serum lipids, muscle enzymes, renal functions and markers of coagulation are affected in patients with a TSH level between 5 and $10 \mathrm{mIU} / \mathrm{l}$. The effects of levothyroxine replacement on these parameters were also evaluated.

\section{Subjects and methods}

\section{Patients}

We prospectively included 15 patients with SH (all female; mean age 47.6 years, range $21-68$ years) and 15 patients with $\mathrm{OH}$ (all female; mean age 52.8 years, range 30-65 years) from Endocrinology and Metabolic Diseases outpatient clinics and 15 healthy individuals (all female; mean age 49.2 years, range 25-61 years) who served as controls. The study groups were selected among a group of patients who had Hashimoto's disease with primary $\mathrm{SH}$ or $\mathrm{OH}$. Hashimoto's disease diagnosis was based on antithyroid peroxidase antibody (TPOAb) positivity and hypoechoic-heterogenous pattern on ultrasonography in the presence of firm goiter and hypothyroidism. SH was defined as elevated TSH levels $(5-10 \mathrm{mU} / \mathrm{l})$ with normal serum FT4 and FT3 levels measured at least two times with a three-month interval, and $\mathrm{OH}$ was defined as grossly elevated TSH levels (TSH $>20 \mathrm{mU} / \mathrm{l}$ ) with low FT4 and FT3 levels with clinical signs and symptoms of hypothyroidism. Controls were defined by normal serum FT3, FT4 and TSH levels. Clinical examination included height and body weight measurements, and body mass index (BMI) which was calculated as weight (kilograms) divided by height (meters) squared $\left(\mathrm{kg} / \mathrm{m}^{2}\right)$. Blood pressure was taken after $10 \mathrm{~min}$ in a resting position. Complete medical histories, including history of bleeding and smoking habits, were recorded. Patients with past or current serious medical diseases including diabetes mellitus and coronary heart disease were excluded. None of the patients were using any medication, including aspirin or diuretics, that might affect the study parameters and none had symptoms and signs of clinical bleeding; none of the individuals were current smokers.

Levothyroxine (LT4) treatment was started in all patients and drug dosage was titrated individually until euthyroidism was obtained. The time intervals between TSH measurements were six weeks, and $25 \mu \mathrm{g}$ increments were made until the desired TSH levels were achieved. Substitutive doses ranged from 50 to $125 \mu \mathrm{g}$ daily with a mean dose of $73 \mu \mathrm{g}$ for the patients with $\mathrm{SH}$ and $105 \mu \mathrm{g}$ for patients with $\mathrm{OH}$. None of the patients received any medication during the study other than LT4. All patients gave informed consent before participating in the study, and the protocol was approved by the Ethics Committee of Ankara University.

Blood urea nitrogen (BUN), creatinine, creatine phosphokinase (CPK), aspartate aminotransferase (AST), lactate dehydrogenase $(\mathrm{LDH})$, total-cholesterol, high density lipoprotein (HDL)-cholesterol, low density lipoprotein (LDL)-cholesterol and triglyceride levels together with bleeding time, prothrombin time (PT), activated partial thromboplastin time (APTT), factor VIII activity, von Willebrand factor activity (vWF), platelet count and clot formation time were evaluated in all subjects just before and three months after the maintenance of euthyroidism in patients with hypothyroidism.

\section{Methods}

Blood samples were collected at 0800-0900 h after overnight fasting. Collected serum and plasma samples were put on ice immediately and processed within 30 min. Thereafter they were kept frozen at $-80^{\circ} \mathrm{C}$. To minimize nonspecific variability, all parameters were evaluated twice in a period of $24 \mathrm{~h}$ (before and after treatment) and the results of the two measurements were averaged for the statistical analysis. Serum FT3, FT4 and TSH levels were measured by commercially available automated chemiluminescence system kits (ACS: 180, Chiron Diagnostics, East Walpole, MA, USA). Sensitivity for the TSH assay was $0.002 \mathrm{mU} / \mathrm{l}$, the intra-assay coefficient of variation (CV) was $0.3-1.4 \%$ and the inter-assay $\mathrm{CV}$ was $0.5-$ $1.9 \%$; all were determined in our laboratory.

BUN (ThermoDMA, East Arlington, TX, USA), creatinine (DMA Inc., East Arlington, TX, USA), CPK, LDH and AST (ThermoDMA), total-cholesterol (Equal Diagnostics, Exton, PA, USA), HDL-cholesterol (Sigma Diagnostics, Poole, Dorset, UK) and triglyceride (Thermo DMA) were measured by automated systems. LDLcholesterol was calculated by the Friedwald formula $\quad(\mathrm{LDL}-$ cholesterol $=$ total-cholesterol $-(\mathrm{HDL}-$ cholesterol plus; triglyceride (TG)/5)). Whole blood analyses were made using an autoanalyser (Coulter LH 500). Factor VIII activity was measured by coagulometric assay (Dade Behring Marburg GmbH, Marburg, Germany). Von Willebrand factor ristocetin cofactor activity was determined by the platelet agglutination method (Dade Behring Marburg GmbH). PT and APTT were measured by coagulation analyzers using kits from Dade Behring Marburg GmbH. The intraassay coefficients of variation were as follows: factor VIII $1.2-3.9 \%$, vWF $1.4-3.1 \%$, PT $0.9-1.4 \%$, APTT $0.8-1.5 \%$ and the inter-assay coefficients of variation were as follows: factor VIII 1.9-4.7\%, vWF 
$1.6-4.4 \%$, PT $1.8-2.6 \%$, APTT $0.7-3.8 \%$, all determined in our laboratory.

\section{Statistical analysis}

Results are expressed as the means \pm S.D. or as the median. ANOVA test-Sheffe's F test were used for the comparison of groups. Tukey test or Bonferroni corrections were used for post-hoc analysis. Mann-Whitney $\mathrm{U}$ test with Bonferroni corrections were used for the comparison of three groups for the data which were not normally distributed. Paired t-test (two sided) for normally distributed data and Mann-Whitney U test for nonparametric distributions were used to evaluate differences in the same group. Significance was defined as $P<0.05$. Data were analyzed using SPSS for windows (version 10.0, SPSS, Chicago, IL, USA).

\section{Results}

\section{Controls and patients: clinical description}

Clinical parameters of the patients and controls are presented in Table 1 . There were no significant differences between the groups for gender, mean age, BMI and for systolic and diastolic blood pressures.

\section{Baseline thyroid functions and hemostatic parameters in the study groups}

Data are given in Table 2. In patients with $\mathrm{OH}$ the mean FT3 level was $3.12 \mathrm{pmol} / \mathrm{l}$, the mean FT4 level was $4.7 \mathrm{pmol} / \mathrm{l}$ and the mean TSH level was $63.3 \mathrm{mU} / \mathrm{l}$. In patients with SH the mean FT3 level was $4.4 \mathrm{pmol} / \mathrm{l}$, the mean FT4 level was $14.8 \mathrm{pmol} / \mathrm{l}$ and the mean TSH level was $7.1 \mathrm{mU} / \mathrm{l}$. In the controls the mean FT3 level was $5.2 \mathrm{pmol} / \mathrm{l}$, the mean FT4 level was $16.4 \mathrm{pmol} / \mathrm{l}$ and the mean TSH level was $1.27 \mathrm{mU} / \mathrm{l}$.

Factor VIII and vWF activities were significantly decreased in the patients with $\mathrm{SH}$ compared with the control group $(P<0.01)$. Patients with $\mathrm{OH}$ showed significantly elevated bleeding time, prothrombin time, APTT and clotting time, and significantly decreased factor VIII activity, vWF levels and platelet counts compared with the controls. vWF and factor VIII activities were lower and APTT duration was higher in the patients with $\mathrm{OH}$ when compared with the patients with SH (Table 2).

\section{Biochemical parameters in patients with $\mathbf{S H}$}

Data are given in Table 3. BUN, creatinine, AST, CPK, LDH, HDL-cholesterol and triglyceride levels were similar in the patient and control groups. Although totalcholesterol and LDL-cholesterol levels were higher in patients with $\mathrm{SH}$ than in controls, they were not statistically significant.

\section{Changes in parameters after levothyroxine treatment}

Overt hypothyroidism Bleeding time, PT, APTT and clotting time decreased significantly $(P<0.05$ for all $)$ and factor VIII activity, vWF activity and platelet count increased significantly in the $\mathrm{OH}$ group after LT4 therapy $(P<0.01, \quad P<0.01$ and $P<0.05$ respectively) (Table 4 ).

Subclinical hypothyroidism Data are depicted in Table 5. Statistically significant increases in factor VIII activity $(137 \pm 23$ vs $111 \pm 26 \%, P<0.01)$ and vWF activity $(133 \pm 19$ vs $102 \pm 22 \%, P<0.01)$ were detected in the SH group after LT4 treatment. None of the biochemical parameters nor the other hemostatic parameters changed with the therapy.

\section{Discussion}

The main finding of the present study is that hypothyroid patients display a distinct pattern of alteration in the coagulation system depending on the severity of the disease. Compared with controls, patients with $\mathrm{OH}$ had higher bleeding time, prothrombin time, activated partial thromboplastin time (APTT) and clotting time and lower factor VIII activity, vWF levels and

Table 1 Clinical characteristics of control subjects and patients with subclinical and overt hypothyroidism. Results are given as either means \pm S.D. or median (range).

\begin{tabular}{lccc}
\hline & Control & Subclinical hypothyroidism & Overt hypothyroidism \\
\hline No. of subjects & 15 & 15 & \\
Gender & All female & All female & 15 \\
Age (years) (range) & $49.2(25-61)$ & $47.6(21-68)$ & \\
TSH (mU/l) (range) & $1.3(0.6-1.9)$ & $7.1 *(5.2-10)$ & $2.8(30-65)$ \\
BMl $\left(\mathrm{kg} / \mathrm{m}^{2}\right)$ & $24.4 \pm 5.3$ & $26.2 \pm 5.4$ & 0 \\
Current smoker $(n)$ & 0 & $132 \pm 15$ & 0 \\
Systolic blood pressure $(\mathrm{mmHg})$ & $124 \pm 13$ & $74 \pm 10$ & $128 \pm 20$ \\
Diastolic blood pressure $(\mathrm{mmHg})$ & $75 \pm 8$ & $72 \pm 15$ & \\
\hline
\end{tabular}

There were no statistically significant differences for these parameters except for $\mathrm{TSH}: * P<0.01$ compared with controls; $† P<0.0001$ compared with controls. 
Table 2 Baseline thyroid functions and hemostatic parameters of the control subjects and patients with subclinical and overt hypothyroidism. Results are presented as means \pm S.D. or median (range).

\begin{tabular}{|c|c|c|c|c|}
\hline Parameters (reference range) & Control $(n=15)$ & Subclinical hypothyroidism $(n=15)$ & Overt hypothyroidism $(n=15)$ & $P$ value \\
\hline FT3 (3.1-7.3 pmol/l) & $5.2 \pm 1.8$ & $4.4 \pm 1.0$ & $3.12 \pm 1.2^{\star *}$ & $<0.01$ \\
\hline FT4 $(10-23 \mathrm{pmol} / \mathrm{l})$ & $16.4 \pm 2.9$ & $14.8 \pm 3.7$ & $4.7 \pm 1.6^{\star *}$ & $<0.0001$ \\
\hline TSH (0.4-4.5 mU/I) (range) & $1.27(0.6-1.9)$ & $7.1 *(5.2-10)$ & $63.3^{\star *}(36-124)$ & $<0.0001$ \\
\hline Bleeding time (2-7 min) & $3.23 \pm 0.56$ & $3.47 \pm 0.67$ & $4.25 \pm 1.8^{* \star}$ & NS \\
\hline Prothrombin time (10-15s) & $11.8 \pm 0.54$ & $12.2 \pm 0.87$ & $13.3 \pm 2.2^{\star *}$ & NS \\
\hline Factor VIII activity (65-135\%) & $126 \pm 29$ & $111 \pm 26^{*}$ & $93 \pm 38^{* *}$ & $<0.01$ \\
\hline vWF $(60-150 \%)$ & $128 \pm 18$ & $102 \pm 22^{*}$ & $87 \pm 24^{\star *}$ & $<0.01$ \\
\hline APTT (15-35s) & $25.7 \pm 7.6$ & $26.9 \pm 8.5$ & $32.5 \pm 4.8^{\star \star}$ & $<0.01$ \\
\hline Platelets $(150-400 \times 1000 / \mu \mathrm{l})$ & $284 \pm 75$ & $269 \pm 60$ & $258 \pm 68^{* *}$ & NS \\
\hline Clotting time $(3-8 \mathrm{~min})$ & $5.9 \pm 1.4$ & $6.8 \pm 1.2$ & $7.3 \pm 3.6^{\star *}$ & NS \\
\hline
\end{tabular}

Comparisons ( $P$ values) are for subclinical and overt hypothyroidism groups.

*Significant difference between controls and subclinical hypothyroid patients, $P=0.05$; **significant difference between controls and overt hypothyroid patients, $P=0.01$; NS, not significant. ANOVA and Tukey test or Bonferroni correction, Mann-Whitney $U$ test with Bonferroni correction.

platelet counts. Even the study population with $\mathrm{SH}$ exhibited lower factor VIII and vWF activities.

The influence of thyroid failure on hemostasis has been studied but is still not very well understood. The effect of hypothyroidism on the coagulation system is based mainly on the studies performed exclusively in patients with $\mathrm{OH}$, presenting conflicting results (1-15). Mostly hypocoagulable states were observed in those studies. Decreased platelet adhesiveness, abnormal bleeding times, decreased levels of factors VIII, IX, XI and XII and a state with low vWF activity resembling acquired von Willebrand disease (vWD) and a bleeding tendency have been described especially in patients with $\mathrm{OH}(4-9)$. On the other hand, some recent studies have suggested a hypercoagulable state, as shown by increases in platelet and factor VII activities and decreases in fibrinolytic activity, in severe hypothyroidism (10-15). Changes in PAI-1 levels have also been shown in patients with hypothyroidism $(12-14)$. In the present study, hemostatic parameters including bleeding time, PT, APTT, factor VIII activity, vWF activity, platelet count and clotting time were found to be altered in patients with $\mathrm{OH}$. Although these findings have suggested a hypocoagulable state, i.e. acquired von Willebrand disease, in our patients no clinical bleeding abnormality was observed. Levothyroxine treatment improved all of these parameters in the patient groups. It could be suggested that generalized diminution in protein synthesis in hypothyroidism may also cause decreases in the coagulation factors. A deficiency of other coagulation factors, including factor VII, V, IX, and X, may have contributed to the prolongation of the APTT in the present patient group.

There are few studies in the English literature covering patients with SH $(12,13,27)$. Muller et al. (12) reported a hypercoagulable state in patients with $\mathrm{SH}$ and they found no change in factor VIII and vWF activities. Chadarevian et al. (13) observed decreased fibrinolytic activity in patients with TSH levels between 10 and $50 \mathrm{mIU} / \mathrm{l}$. In a recent study, Canturk et al. reported increased fibrinogen, PAI-1 and factor VII and decreased antithrombin III concentrations in a group of patients with SH (27). They also found improvements in these parameters with LT4 treatment, and came to the conclusion that $\mathrm{SH}$ is a hypofibrinolytic hypercoagulable state. In contrast to these studies, our patients with SH exhibited a hypocoagulable state

Table 3 Baseline biochemical parameters of the control subjects and the patients with subclinical hypothyroidism. Results are means \pm S.D. or median (range).

\begin{tabular}{|c|c|c|c|}
\hline Parameters (reference range) & Control $(n=15)$ & Subclinical hypothyroidism $(n=15)$ & $P$ value \\
\hline FT3 (3.1-7.3 pmol/l) & $5.2 \pm 1.8$ & $4.4 \pm 1.0$ & NS \\
\hline FT4 $(10-23 \mathrm{pmol} / \mathrm{l})$ & $16.4 \pm 2.9$ & $14.8 \pm 3.7$ & NS \\
\hline TSH (0.4-4.5 mU/I) (range) & $1.27(0.6-1.9)$ & $7.1(5.2-10)$ & $<0.0001$ \\
\hline BUN (8-23 mg/dl) & $11.8 \pm 3.7$ & $12.3 \pm 3.6$ & NS \\
\hline Creatinine $(0.4-1.2 \mathrm{mg} / \mathrm{dl})$ & $0.7 \pm 0.2$ & $0.8 \pm 0.4$ & NS \\
\hline AST $(13-40 \mathrm{IU} / \mathrm{I})$ & $23 \pm 8$ & $21 \pm 9$ & NS \\
\hline CPK (24-195IU/I) & $86 \pm 31$ & $90 \pm 25$ & NS \\
\hline LDH (110-210 IU/I) & $138 \pm 42$ & $145 \pm 35$ & NS \\
\hline Total-cholesterol (120-200 mg/dl) & $161 \pm 32$ & $173 \pm 41$ & NS \\
\hline LDL-cholesterol (70-130 mg/dl) & $83 \pm 33$ & $96 \pm 43$ & NS \\
\hline HDL-cholesterol (40-80 mg/dl) & $45 \pm 10$ & $44 \pm 10$ & NS \\
\hline Triglyceride $(60-200 \mathrm{mg} / \mathrm{dl})$ & $148 \pm 69$ & $147 \pm 87$ & NS \\
\hline
\end{tabular}

NS, not significant ( $t$-test or Mann-Whitney $U$ test). 
Table 4 Hemostatic parameters in patients with overt hypothyroidism before and after levothyroxine treatment. Results are means \pm S.D. or median (range).

\begin{tabular}{lccc}
\hline Parameter (normals values) & Before levothyroxine & After levothyroxine & $P$ value \\
\hline FT3 $(3.1-7.3 \mathrm{pmol} / \mathrm{l})$ & $3.12 \pm 1.2$ & $4.7 \pm 0.85$ & $<0.01$ \\
FT4 $(10-23 \mathrm{pmol} / \mathrm{l})$ & $4.7 \pm 1.6$ & $17.5 \pm 3.3$ & $<0.001$ \\
TSH $(0.4-4.5 \mathrm{mU} / \mathrm{l})$ (range) & $63.3(36-124)$ & $2.8(0.5-3.6)$ & $<0.01$ \\
Bleeding time $(2-7$ min) & $4.25 \pm 1.8$ & $3.29 \pm 0.7$ & $<0.05$ \\
Prothrombin time $(10-15 \mathrm{~s})$ & $13.3 \pm 2.2$ & $10.5 \pm 1.1$ & $<0.05$ \\
Factor VIII activity $(65-135 \%)$ & $93 \pm 38$ & $134 \pm 33$ & $<0.01$ \\
vWF $(60-150 \%)$ & $87 \pm 24$ & $138 \pm 21$ & $<0.01$ \\
APTT $(15-35 \mathrm{~s})$ & $32.5 \pm 4.8$ & $26.7 \pm 3.1$ & $<0.05$ \\
Platelets $(150-400 \times 1000 / \mu \mathrm{l})$ & $258 \pm 68$ & $289 \pm 69$ & $<0.05$ \\
Clotting time $(3-8 \mathrm{~min})$ & $7.3 \pm 3.6$ & $6.4 \pm 0.9$ & $<0.05$ \\
\hline
\end{tabular}

$P$ value by $t$-test or Mann-Whitney $U$ test.

Table 5 Biochemical and hemostatic parameters in patients with subclinical hypothyroidism before and after levothyroxine treatment. Results are means \pm S.D. or median (range).

\begin{tabular}{|c|c|c|c|}
\hline Parameters (normal values) & Before levothyroxine & After levothyroxine & $P$ value \\
\hline FT3 (3.1-7.3 pmol/l) & $4.4 \pm 1.0$ & $4.7 \pm 0.75$ & NS \\
\hline FT4 (10-23 pmol/l) & $14.8 \pm 3.7$ & $16.5 \pm 3.2$ & NS \\
\hline TSH (0.4-4.5 mU/I) (range) & $7.1(5.2-10)$ & $2.2(0.71-3.1)$ & $<0.01$ \\
\hline BUN (8-23 mg/dl) & $12.3 \pm 3.6$ & $11.5 \pm 2.9$ & NS \\
\hline Creatinine $(0.4-1.2 \mathrm{mg} / \mathrm{dl})$ & $0.8 \pm 0.4$ & $0.7 \pm 0.18$ & NS \\
\hline AST (13-40 IU/I) & $21 \pm 9$ & $20 \pm 8$ & NS \\
\hline CPK (24-195 IU/I) & $90 \pm 25$ & $87 \pm 23$ & NS \\
\hline LDH (110-210 IU/I) & $145 \pm 35$ & $142 \pm 23$ & NS \\
\hline Total-cholesterol (120-200 mg/dl) & $173 \pm 41$ & $167 \pm 46$ & NS \\
\hline LDL-cholesterol (70-130 mg/dl) & $96 \pm 43$ & $94 \pm 47$ & NS \\
\hline HDL-cholesterol (40-80 mg/dl) & $44 \pm 10$ & $43 \pm 10$ & NS \\
\hline Triglyceride (60-200 mg/dl) & $147 \pm 87$ & $152 \pm 105$ & NS \\
\hline Bleeding time $(2-7 \mathrm{~min})$ & $3.47 \pm 0.67$ & $3.07 \pm 0.7$ & NS \\
\hline Prothrombin time $(10-15 \mathrm{~s})$ & $12.2 \pm 0.87$ & $11.2 \pm 1.1$ & NS \\
\hline Factor VIII activity (65-135\%) & $111 \pm 26$ & $137 \pm 23$ & $<0.01$ \\
\hline vWF $(60-150 \%)$ & $102 \pm 22$ & $133 \pm 19$ & $<0.01$ \\
\hline APTT (15-35s) & $26.9 \pm 8.5$ & $24.5 \pm 6.2$ & NS \\
\hline Platelets $(150-400 \times 1000 / \mu \mathrm{l})$ & $269 \pm 60$ & $275 \pm 70$ & NS \\
\hline Clotting time $(3-8 \mathrm{~min})$ & $6.8 \pm 1.2$ & $5.71 \pm 1.9$ & NS \\
\hline
\end{tabular}

NS, not significant ( $t$-test or Mann-Whitney $U$ test).

as shown by decreased factor VIII and vWF activities, and both factors were improved with LT4 treatment.

Several factors may affect coagulation including age, sex, smoking, drugs and other medical conditions. In the present study we only included non-smoking female patients and compared their results with matched healthy controls. Since none of the individuals had any conditions that might alter the evaluated parameters, the only distinct aspect in the study was the thyroid hormone levels. Thus it seems that thyroid hormones have a direct influence on hemostatic factors. The mechanisms by which low thyroid hormone levels may lead to alterations in hemostasis are not well established and are conflicting. Chadarevian et al. evaluated the relationship between fibrinogen, D-dimer and FT4 in their two in vitro studies and found a negative and independent relationship between FT4 and the mentioned parameters (10, 11). They concluded that FT4 plays a physiological role in the regulation of the hemostatic equilibrium and that low
FT4 levels are associated with a hypercoagulable state. On the other hand, in a very recent in vitro study, a direct stimulatory effect of triiodothyronine on fibrinogen synthesis has been observed (16).

It appears that altered primary hemostatis is a feature of hypothyroidism and levothyroxine replacement therapy resolves these abnormalities in both overt and subclinical hypothyroidism. It is difficult to draw a firm conclusion from our results because of the relatively small number in the study population but we suggest that, although clinically insignificant, this hypocoagulable state should be kept in mind in patients who present with bleeding symptoms and signs.

In the present study, serum total-cholesterol, LDLcholesterol and HDL-cholesterol levels of patients with $\mathrm{SH}$ were not different from the controls. Despite various assessments of the literature, the relationship between SH, serum lipids and atherosclerosis is still ambiguous $(17,20-22)$. Some cross-sectional studies suggested that serum cholesterol levels are significantly higher 
in individuals with mild thyroid failure but some others did not $(17-22)$. Another debate in patients with SH is the need for replacement treatment with thyroid hormones. Although results of several studies suggest that thyroid hormone substitution therapy reduced total- and LDL-cholesterol levels in patients with $\mathrm{SH}$, this finding has not been confirmed by others (2837). Several alterations in muscle function, skeletal muscle abnormalities, and renal function abnormalities have been reported in both subclinical and overt hypothyroidism (23-26). We could not find any abnormalities in renal function tests or muscle enzyme levels in SH patients, and no changes were observed after LT4 treatment in this group. None of the biochemical parameters, including the serum lipid levels, changed with LT4 replacement therapy in the patient group with $\mathrm{SH}$ in the present study. This may be due to the relatively mildly elevated initial TSH levels of the patients, since the TSH levels were all below $10 \mathrm{IU} / \mathrm{l}$ in our patients. Although it is difficult to make a strong suggestion because of the small number in the study population, regarding all the parameters studied in the patients with $\mathrm{SH}$ in the present study, we, like others, also think that treating asymptomatic, otherwise healthy SH patients is not necessary $(17,28)$.

In conclusion, a tendency to hypocoagulable state can be seen in both subclinical and overt hypothyroidism. This alteration in hemostasis is reversed by LT4 replacement. However, the clinical significance of these changes remains to be elucidated. On the other hand, since patients with a TSH level below $10 \mathrm{mIU} / \mathrm{l}$ show no abnormalities regarding serum lipids, muscle enzymes and renal functions and do not benefit from LT4 administration, treatment can be preserved for those patients who have potentially reversible symptoms, hypercholesterolemia or a high risk of progression to $\mathrm{OH}$ as revealed by older age.

\section{References}

1 Ford HC \& Carter JM. Haemostasis in hypothyroidism. Postgraduate Medical Journal 199066 280-284.

2 Myrub B, Bregengard C \& Faber J. Primary haemostasis in thyroid disease. Journal of Internal Medicine 1995238 59-63.

3 Hofbauer LC \& Heufelder AE. Coagulation disorders in thyroid diseases. European Journal of Endocrinology $19971361-7$.

4 Jakway JL. Acquired von Willebrand's disease. Hematology/Oncology Clinics of North America 19926 1409-1419.

5 Palareti G, Biagi G, Legnani C, Bianchi D, Serra D, Savini R \& Coccheri S. Association of reduced factor VIII with impaired platelet reactivity to adrenalin and collagen after total thyroidectomy. Thrombosis and Haemostasis 198962 1053-1056.

6 Attivissimo LA, Lichtman SM \& Klein I. Acquired von Willebrand's syndrome causing a hemorrhagic diathesis in a patient with hypothyroidism. Thyroid 19955 399-401.

7 Michiels JJ, Schroyens W, Berneman Z \& van der Planken M. Acquired von Willebrand syndrome type 1 in hypothyroidism: reversal after treatment with thyroxine. Clinical and Applied Thrombosis Hemostasis 20017 113-115.
8 Setian N, Tanaka CM, Damiani D, Dichtchekenian V, Carneiro JD \& D'Amico EA. Hypopituitarism, deficiency of factors V and VIII and von Willebrand factor: an uncommon association. Journal of Pediatric Endocrinology and Metabolism 200215 331-333.

9 Masunaga R, Nagasaka A, Nakai A, Kotake M, Sawai Y, Oda N, Mokuno T, Shimazaki K, Hayakawa N, Kato R, Hirano E, Hagiwara M \& Hidaka H. Alteration of platelet aggregation in patients with thyroid disorders. Metabolism $1997461128-1131$.

10 Chadarevian R, Bruckert E, Ankri A, Beucler I, Giral P \& Turpin G. Relationship between thyroid hormones and plasma D-dimer levels. Thrombosis Haemostasis 199879 99-103.

11 Chadarevian R, Bruckert E, Giral P \& Turpin G. Relationship between thyroid hormones and fibrinogen levels. Blood Coagulation and Fibrinolysis $1999 \mathbf{1 0} 481-486$.

12 Muller B, Tsakiris D, Roth C, Guglielmetti M, Staub J \& Marbet M. Haemeostatic profile in hypothyroidism as potential risk factor for vascular or thrombotic disease. European Journal of Clinical Investigation 200131 131-137.

13 Chadarevian R, Bruckert E, Leenhardt L, Giral P, Ankri A \& Turpin G. Components of fibrinolytic system are differently altered in moderate and severe hypothyroidism. Journal of Clinical Endocrinology and Metabolism $200186732-737$.

14 Erem C, Kavgaci H, Ersoz HO, Hacihasanoglu A, Ukinc K, Karti SS, Deger O \& Telatari M. Blood coagulation and fibrinolytic activity in hypothyroidism. International Journal of Clinical Practice 2003 $\mathbf{5 7} 78-81$.

15 Rennie JA, Bewsher PD, Murchison LE \& Ogston D. Coagulation and fibrinolysis in thyroid disease. Acta Haematologia $1978 \mathbf{5 9}$ 171-177.

16 Shih CH, Chen SL, Yen CC, Huang YH, Chen CD, Lee YS \& Lin KH. Thyroid hormone receptor-dependent transcriptional regulation of fibrinogen and coagulation proteins. Journal of Clinical Endocrinology and Metabolism $20041452804-2814$.

17 Surks MI, Ortiz E, Daniels GH, Savin CT, Col NF, Cobin RH, Franklyn JA, Hershman JM, Burman KD, Denke MA, Gorman C, Cooper RS \& Weissman NJ. Subclinical thyroid disease: scientific review and guidelines for diagnosis and management. Journal of the American Medical Association $2004291228-238$.

18 Woeber KA. Subclinical thyroid dysfunction. Archives of Internal Medicine 1997157 1065-1068.

19 Arem R \& Escalante D. Subclinical hypothyroidism: epidemiology, diagnosis, and significance. Advances in Internal Medicine 199641 213-250.

20 Althaus BU, Staub JJ, Ryff-de Leche A, Oberhansli A \& Stahelin HB. LDL/HDL changes in subclinical hypothyroidism: possible risk factor for coronary heart disease. Clinical Endocrinology $1988 \mathbf{2 8} 157-163$.

21 Hak AE, Pols HA, Visser TJ, Drexhage HA, Hofman A \& Wittem A. Subclinical hypothyroidism is an independent risk factor for atherosclerosis and myocardial infarction in elderly women: the Rotterdam study. Annals of Internal Medicine 2000132 270-278.

22 Vanderpump MPJ, Tunbridge WMG, French JM, Appleton D, Bates D, Clark F, Grimley Evans J, Rodgers H, Tunbridge F \& Young ET. The development of ischemic heart disease in relation to autoimmune thyroid disease in a 20-year follow-up study of an English community. Thyroid 19966 155-160.

23 Verhelst J, Berwaerts J, Marescau B, Abs R, Neels H, Mahler C \& De Deyn PP. Serum creatine, creatinine and other guanidino compounds in patients with thyroid dysfunction. Metabolism 199746 1063-1067.

24 Beyer IW, Karmali R, Demeester-Mirkine N, Cogan E \& Fuss MJ. Serum creatine kinase levels in overt and subclinical hypothyroidism. Thyroid $1998 \mathbf{8} 1029-1031$.

25 Monzani F, Caraccio N, Siciliano G, Manca L, Murri L \& Ferrannini E. Clinical and biochemical features of muscle dysfunction in subclinical hypothyroidism. Journal of Clinical Endocrinology and Metabolism 199782 3315-3318.

26 Villabona C, Sahun M, Roca M, Mora J, Gomez N, Gomez JM \& Soler J. Blood volumes and renal function in overt and subclinical 
primary hypothyroidism. American Journal of Medical Sciences $1999318277-280$.

27 Canturk Z, Cetinarslan B, Tarkun I, Canturk NZ, Ozden M \& Duman C. Hemostatic system as a risk factor for cardiovascular disease in women with subclinical hypothyroidism. Thyroid $200313971-977$.

28 Chu JW \& Crapo LM. The treatment of subclinical hypothyroidism is seldom necessary. Journal of Clinical Endocrinology and Metabolism $2001864591-4599$.

29 Meier C, Staub JJ, Roth CB, Guglielmetti M, Kunz M, Miserez AR, Drewe J, Huber P, Herzog R \& Muller B. TSH-controlled L-thyroxine therapy reduces cholesterol levels and clinical symptoms in subclinical hypothyroidism: a double-blind, placebo-controlled trial (Basel Thyroid Study). Journal of Clinical Endocrinology and Metabolism 200186 4860-4866.

30 McDermott MT \& Ridgway EC. Subclinical hypothyroidism is mild thyroid failure and should be treated. Journal of Clinical Endocrinology and Metabolism 200186 4585-4590.

31 Danese MD, Ladenson PW. Meinert CL \& Powe NR. Clinical Review 115: Effect of thyroxine therapy on serum lipoproteins in patients with mild thyroid failure: a quantitative review of the literature. Journal of Clinical Endocrinology and Metabolism 200085 2993-3001.

32 Bell GM, Todd WTA, Forfar JC, Martyn C, Wathen CG, Gow S, Riemersma R \& Toft AD. End-organ responses to thyroxine therapy in subclinical hypothyroidism. Clinical Endocrinology $19852283-89$.

33 Cooper DS, Halpern R, Wood LC, Levin AA \& Ridgway EC. L-Thyroxine therapy in subclinical hypothyroidism. A double-blind, placebo-controlled trial. Annals of Internal Medicine $1984 \mathbf{1 0 1}$ $18-24$.

34 Franklyn JA, Daykin J, Betteridge J, Hughes EA, Holder R, Jones SR \& Sheppard MC. Thyroxine replacement therapy and circulating lipid concentrations. Clinical Endocrinology 199338 453-459.

35 Nystrom E, Caidahl K, Fager G, Wikkelso C, Lundberg PA \& Lindstedt G. A double-blind cross-over 12-month study of L-thyroxine treatment of women with 'subclinical' hypothyroidism. Clinical Endocrinology $19882963-75$.

36 Kong WM, Sheikh MH, Lumb PJ, Freedman DB, Danielle B, Crook M, Dore CJ \& Finer N. A 6-month randomized trial of thyroxine treatment in women with mild subclinical hypothyroidism. American Journal of Medicine $2002112348-354$.

37 Caraccio N. Ferrannini E \& Monzani F. Lipoprotein profile in subclinical hypothyroidism: response to levothyroxine replacement, a randomized placebo-controlled study. Journal of Clinical Endocrinology and Metabolism 200287 1533-1538.

Received 15 April 2004

Accepted 23 November 2004 